\title{
The frequency of one-day abnormal returns and price fluctuations in the forex
}

\section{Guglielmo Maria Caporale, Alex Plastun \& Viktor Oliinyk}

To cite this article: Guglielmo Maria Caporale, Alex Plastun \& Viktor Oliinyk (2021) The frequency of one-day abnormal returns and price fluctuations in the forex, Journal of Applied Economics, 24:1, 401-415, DOI: 10.1080/15140326.2021.1953914

To link to this article: https://doi.org/10.1080/15140326.2021.1953914

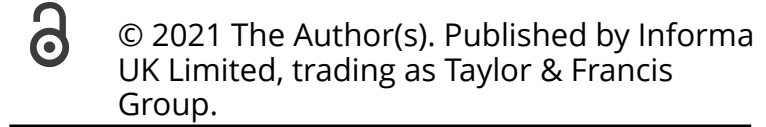
UK Limited, trading as Taylor \& Francis Group.

\section{+ View supplementary material $\widetilde{ }$}

曲 Published online: 02 Sep 2021.

Submit your article to this journal

Џlll Article views: 108

Q View related articles $\sqsubset$

View Crossmark data $₫$ 


\title{
The frequency of one-day abnormal returns and price fluctuations in the forex
}

\author{
Guglielmo Maria Caporale (D) ${ }^{\mathrm{a}}$, Alex Plastun (10) ${ }^{\mathrm{b}}$ and Viktor Oliinyk ${ }^{\mathrm{c}}$
}

${ }^{\mathrm{a} D e p a r t m e n t ~ o f ~ E c o n o m i c s ~ a n d ~ F i n a n c e, ~ B r u n e l ~ U n i v e r s i t y, ~ L o n d o n, ~ U n i t e d ~ K i n g d o m ; ~}{ }^{\mathrm{b}}$ Department of International Economic Relations, Sumy State University, Sumy, Ukraine; 'Chair of Economic Cybernetics, Sumy State University, Sumy, Ukraine

\begin{abstract}
This paper analyses the explanatory power of the frequency of abnormal returns in the FOREX over the period 1994-2019. The following hypotheses are tested: frequency of abnormal returns is asignificant driver of price movements $(\mathrm{H} 1)$; it does not exhibit seasonal patterns $(\mathrm{H} 2)$; it is stable over time $(\mathrm{H} 3)$. For our purposes avariety of statistical methods are applied including ADF, PP and KPSS tests, Granger causality tests, correlation analysis, regression analysis, Probit and Logit regression models. No evidence is found of either seasonal patterns or instability. However, there appears to be astrong positive (negative) relationship between returns in the FOREX and the frequency of positive (negative) abnormal returns. On the whole, the results suggest that the latter is an important driver of price dynamics in the FOREX, is informative about crises and can be the basis of profitable trading strategies, which is inconsistent with market efficiency.
\end{abstract}

\section{ARTICLE HISTORY}

Received 16 April 2021

Accepted 2 July 2021

\section{KEYWORDS}

FOREX; anomalies; price dynamics; frequency of abnormal returns

\section{Introduction}

The FOREX is one of the most liquid (with 6 USD tn daily turnover) and efficient financial markets (Kallianiotis, 2017; Oh, Kim, \& Eom, 2006; Serbinenko \& Rachev, 2009). Nevertheless, several studies have attempted to detect anomalies in the behaviour of exchange rates such as abnormal returns with the associated contrarian or momentum patterns (Caporale, Gil-Alana, \& Plastun, 2018; Parikakis \& Syriopoulos, 2008), and also investigated whether they can be used as an early warning indicators for financial crises (e.g., the East Asian and the Russian crises of the 1990s, the Dotcom bubble of 19972001, and the global financial crisis of 2007-8). The various methods used include price trends and persistence analysis, trade volumes and price volatility analysis, correlation between assets etc. (Bremer, Hiraki, \& Sweeney, 1997; Eross, McGroarty, Urquhart, \& Wolfe, 2019; Granger \& Newbold, 1986).

The present paper takes instead a different approach to analyse the explanatory power of the frequency of abnormal returns; this issue has been previously examined in the case of stock markets (Angelovska, 2016; Caporale \& Plastun, 2019) and cryptocurrency

CONTACT Guglielmo Maria Caporale Guglielmo-Maria.Caporale@brunel.ac.uk $@$ Department of Economics and Finance, Brunel University, London UB8 3PH.

$(4$ Supplemental data for this article can be accessed here. 
markets (Caporale, Plastun, \& Oliinyk, 2019), but not in that of the FOREX, which is the focus of this study.

The main novelty of this paper is the use of the frequency of abnormal returns as a useful source of information about price movements in the FOREX market. Abnormal returns are detected using a dynamic trigger approach. Then the following hypotheses are tested: (i) their frequency is a significant driver of price movements (H1); (ii) it does not exhibit seasonal patterns (H2); (iii) it is stable over time (H3). For our purposes a variety of statistical methods (both parametric and non-parametric) are applied including ADF, Phillips and Perron and KPSS tests, Granger causality tests, correlation analysis, (multiple) regression analysis, Probit and Logit regression models. Although some related work had already been carried out by Caporale and Plastun (2019) and Caporale et al. (2019) for stock prices and cryptocurrencies, the present paper is a much more extensive investigation which yields more thorough results for an issue which to date had been virtually unexplored in the case of the FOREX market. In particular, the empirical analysis adds Probit and Logit regression models as well as a number of diagnostic tests including Lilliefors's test, the Durbin-Watson's test, White's test, Ramsey's Regression Equation Specification Error Test (RESET) and Chow's test. Also, it examines the additional issue of stability (see $\mathrm{H} 3$ above).

The remainder of the paper is organised as follows. Section 2 contains a brief review of the relevant literature. Section 3 describes the methodology. Section 4 discusses the empirical results. Section 5 offers some concluding remarks.

\section{Literature review}

There exists an extensive literature investigating one-day abnormal price changes. Various explanations have been suggested for their occurrence. For instance, Govindaraj, Livnat, Savor, and Zhaoe (2014) and Jin, Livnat, and Zhang (2012) examined the role of new information, noise or liquidity trades. Bartos (2015) argued that new information is immediately absorbed without significant price effects. The most popular explanations rely on cognitive traps and biases (Barberis, Shleifer, \& Vishny, 1998), as well as emotions and psychological aspects of trading and investment (Daniel, Hirshleifer, \& Subrahmanyam, 1998; Griffin \& Tversky, 1992; Madura \& Richie, 2004). Rao and Gertler (1999) and Hong and Stein (1999) see their roots in the presence and activity of "noise" traders. Duran and Caginalp (2007) argued that abnormal returns result from the use of technical and fundamental analysis by investors for decisionmaking. Other studies have considered the impact of market liquidity (Jegadeesh \& Titman, 1993), news (Kocenda \& Moravcová, 2018) etc.

Abnormal price changes can generate different price patterns. Atkins and Dyl (1990) and Bremer et al. (1997) found contrarian effects (price reversals) after large price changes. By contrast, Cox and Peterson (1994) did not detect a negative correlation between abnormal returns on the day prices fall and the following three days. Schnusenberg and Madura (2001) and Lasfer, Melnik, and Thomas (2003) provided evidence of momentum effects. Savor (2012) and Govindaraj et al. (2014) found both effects in the US stock market (momentum effects when analysts issue revisions or price reversals after large daily price shocks). 
Various other studies also analyse some of the implications of abnormal returns. For instance, Pritamani and Singal (2001) showed that information about large price changes can be used to design profitable trading strategies. Govindaraj et al. (2014) also found that a trading strategy based on these effects can generate significant excess returns. Similar conclusions were reached by Caporale et al. (2018), who tested price effects after abnormal price returns in different financial markets; they showed that the reversal effect is exploitable in the stock market, whilst the momentum effect produces profits in the case of the FOREX and commodity markets. By contrast, Cox and Peterson (1994) and Lasfer et al. (2003) argued that trading strategies based on price patterns after one-day abnormal returns can hardly be profitable because of the presence of trading costs and the relatively small size of price reversals. According to Sandoval and Franca (2012), abnormal price changes can also be informative about future price movements and be used as a crisis identifier.

There is a much smaller literature on the FOREX market and how prices behave in response to various types of shocks. Some contributions are event studies (Chuck, Kwok, \& Brooks, 1990). Others analyse the impact of news. For instance, Kocenda and Moravcová (2018) found that prices in FOREX react not only after, but also before news releases. Andersen, Bollerslev, Diebold, and Vega (2003) reported that bad news have a greater impact than good news. Price predictability in the FOREX was analysed by Lyons (1995) and Evans and Lyons (2002), who found that order flows can explain exchange rate movements much more effectively than fundamentals. Wan and Kao (2009) explored contrarian effects in the FOREX, and Chelley-Steeley and Tsorakidis (2013) carried out a bid-ask spread analysis to detect the most attractive currency pair for speculators. The evolution of trading rule profits was explored by Olson (2004).

Typically abnormal returns are analysed in the case of stock markets (Atkins \& Dyl, 1990; Cox \& Peterson, 1994; Bremer et al., 1997; Govindaraj et al., 2014; Sandoval \& Franca, 2012; Angelovska, 2016 and many others) or cryptocurrency markets; in particular, Caporale and Plastun (2019) and Caporale et al. (2019) showed that the frequency of abnormal returns can provide useful information in the case of the cryptocurrency markets. Much less evidence is available for the FOREX, which is the focus of the present paper. An exception is the study carried out by Parikakis and Syriopoulos (2008), who investigated patterns following excess one-day fluctuations for various currencies and found that a contrarian strategy is profitable in the FOREX market. In comparison to Caporale and Plastun (2019) and Caporale et al. (2019) the present study estimates a much wider set of models and carries out various additional diagnostic tests with the aim of obtaining a more thorough picture in the case of the FOREX market, for which this type of analysis had not been previously carried out. In addition, it also explores the issue of whether or not the frequency of abnormal returns is stable over time, thus shedding new light on the empirical relevance of the Adaptive Expectations Hypothesis.

\section{Methodology}

To analyse the frequency of abnormal returns and their role as drivers of price dynamics we use daily and monthly data for the main exchange rates, specifically for EURUSD, GBRUSD, USDJPY, EURJPY, GBPCHF, AUDUSD and USDCAD over the period 03.01.1994-28.05.2019; the data source is Yahoo! Finance (https://finance. 
yahoo.com). In order to provide a comprehensive analysis of the FOREX market we choose the most liquid exchange rates, namely EURUSD, GBRUSD and USDJPY, as well as two leading "commodity currencies" and some cross-rates, namely EURJPY and GBPCHF.

There are two main approaches to detecting abnormal returns, namely a static one (which uses a specific threshold as an abnormal price criterion, as in Bremer \& Sweeney, 1991) and a dynamic one (which is based on relative values - normally abnormal returns are defined on the basis of the number of standard deviations to be added to the average return as in (Caporale et al., 2018). Since they can perform rather differently depending on the dataset (Caporale et al., 2018) the first step is to choose the most appropriate method for the data in hand.

Returns (namely, the percentage price change over the period of interest) are defined as:

$$
R_{t}=\left(P_{t}-P_{t-1}\right) / P_{t-1}
$$

where $R_{t}$ stands for returns, and $P_{t}$ and $P_{t-1}$ are the close prices of the current and previous day. The static approach introduced by Sandoval and Franca (2012) and developed by Caporale and Plastun (2019) is based on creating histograms with values $10 \%$ above or below those of the population; thresholds are then obtained for both positive and negative abnormal returns, and periods can be identified when returns were above or equal to the threshold. The choice of the threshold for detecting abnormal returns is driven by the need to have a sufficient number of observations for the analysis to be carried out.

In the dynamic trigger approach (Caporale et al., 2018; Wong, 1997) abnormal price changes are defined by the following inequality:

$$
R_{i}>\left(\bar{R}+k \times \delta_{n}\right)
$$

and negative abnormal price change are defined as:

$$
R_{i}<\left(\bar{R}_{n}-k \times \delta_{n}\right)
$$

where $k$ is the number of standard deviations used to identify them (specifically, $k=1$ ), $\overline{R_{n}}$ is the average size of daily returns for period $n$ and $\delta_{n}$ is the standard deviation of daily returns for period $n$

Both procedures (static and dynamic) generate a data set for the frequency of abnormal returns (at a monthly frequency), which is then divided into 4 subsets including respectively the frequency of negative and positive abnormal returns, the difference between them and the overall frequency of abnormal returns (positive as well as negative).

Then the following hypotheses are tested:

(i) the frequency of abnormal returns is a significant driver of price movements (H1),

(ii) it does not exhibit seasonal patterns $(\mathrm{H} 2)$,

(iii) it is stable over time (H3). 
To test H1, we regress monthly returns (and any observed momentum or contrarian effects) against the frequency of abnormal returns over a 1-month period; specifically we estimate the following regressions:

$$
\mathrm{Y}_{\mathrm{t}}=\mathrm{a}_{0}+\mathrm{a}_{1} \mathrm{~F}_{\mathrm{t}}^{+}+\mathrm{a}_{2} \mathrm{~F}_{\mathrm{t}}^{-}+\varepsilon_{\mathrm{t}}
$$

where $Y_{t}$ - returns on day $t$;

$\mathrm{a}_{0}$-mean return;

$a_{1}()-$ coefficients on the frequency of positive and negative abnormal returns respectively;

$\left(\mathrm{F}_{\mathrm{t}}^{-}\right)$- the number of positive (negative) abnormal returns days during a period $t$;

$\varepsilon_{\mathrm{t}}-$ Random error term at time $t$.

$$
\mathrm{Y}_{\mathrm{t}}=\mathrm{b}_{0}+\mathrm{b}_{1} \mathrm{~F}_{\mathrm{t}}^{\text {delta }}+\varepsilon_{\mathrm{t}}
$$

$b_{1}$ - coefficient on the delta frequency;

$\mathrm{F}_{\mathrm{t}}^{\text {delta }}$ - the difference between the number of positive (negative) abnormal returns days during a period $t$.

As an alternative, Logit and Probit regressions are run. These are binary choice models producing estimates of the probability that the dependent variable will take the value 1 depending on the values of the regressors. In a Logit regression, it is assumed that the probability of event y being equal to 1 is given by $P\{y=1 x\}=f(z)$, where $f(z)=$ $\frac{1}{1-\exp (-z)}-$ is the logistic function, and the parameter $\mathrm{z}$ is determined on the basis of regression (6).

$$
\mathrm{z}_{\mathrm{t}}=\mathrm{a}_{0}+\mathrm{a}_{1} \mathrm{~F}_{\mathrm{t}}^{+}+\mathrm{a}_{2} \mathrm{~F}_{\mathrm{t}}^{-}+\varepsilon_{\mathrm{t}}
$$

where $z_{t}$ is a binary value equal to 1 if the return on day $t$ increased compared to day $t-1$; otherwise, this value is 0 .

$\mathrm{a}_{0}$ - constant.

If the probability predicted by the model $P(x)>0.5$, then the dependent variable is equal to 1 , whilst $P(x) \leq 0.5$ - implies that it is equal to 0 . The Probit regression is based on the assumption that the variable under investigation is normally distributed.

The size, sign and statistical significance of the coefficients provide information about the possible effects of the frequency of abnormal returns on returns in the FOREX. A number of diagnostic tests are also carried out; these include Lilliefors's test, DurbinWatson's test, White's test, Ramsey's Regression Equation Specification Error Test (RESET) and Chow's test. Table 1 specifies the null hypothesis in each case.

Table 1. Diagnostic tests.

\begin{tabular}{ll}
\hline Tests & \multicolumn{1}{c}{ Null hypothesis } \\
\hline Lilliefors's test & Normal distribution \\
Durbin-Watson's test & No autocorrelation \\
White's test & No heteroscedasticity \\
Ramsey's Regression Equation Specification Error Test (RESET) & Adequate functional form \\
Chow's test & No structural change \\
\hline $\begin{array}{l}\text { This table presents data Diagnostic tests and Null hypotheses they test. The first column reports names } \\
\text { of the tests; the second column shows Null hypothesis formulation. }\end{array}$
\end{tabular}


To test $\mathrm{H} 2$ and $\mathrm{H} 3$ we perform both parametric (ANOVA analysis) and nonparametric (Kruskal-Wallis) tests.

\section{Empirical results}

As a first step, one needs to choose between the static and dynamic approaches to calculate abnormal returns. For this purpose the EURUSD exchange rate is used. Table 2 reports the correlation coefficients between the two sets of results.

As can be seen, in the case of the frequency delta parameter the correlation is rather high; however, the other correlation coefficients imply a sizeable difference between the static and dynamic results. To choose between the two, we focus on the correlation between the frequency of abnormal returns and both close prices and returns. The results are reported in Table 3.

As can be seen the frequency of abnormal returns is correlated only with monthly returns, and consequently only these will be used to test the hypotheses of interest; further, the dynamic approach produces higher correlations for the frequency of negative and positive abnormal returns, and therefore will be used in the remainder of the analysis to detect abnormal returns. Finally, since the overall frequency of abnormal returns does not appear to be informative about price dynamics, only the frequency of negative and positive abnormal returns, and the frequency delta, will be used.

ADF tests (Dickey \& Fuller, 1979) carried out on the series of interest (see Appendix C, Tables C.1-C.7) imply a rejection of the unit root null in all cases (i.e., stationarity). As a robustness check we have also carried out the Phillips and Perron (Phillips \& Perron, 1988) and Kwiatkowski et al. (Kwiatkowski, Phillips, Schmidt, \& Shin, 1992) tests. The results are presented in Appendix C, Tables C.1-C.7, and confirm the stationarity of the series. Table 4 reports the correlation coefficients for the number of negative and positive

Table 2. Correlation analysis of data from the static and dynamic approaches.

\begin{tabular}{|c|c|c|c|c|}
\hline Data & $\begin{array}{l}\text { Frequency of negative } \\
\text { abnormal returns }\end{array}$ & $\begin{array}{l}\text { Frequency of positive } \\
\text { abnormal returns }\end{array}$ & $\begin{array}{l}\text { Frequency } \\
\text { delta }\end{array}$ & $\begin{array}{l}\text { Overall frequency of } \\
\text { abnormal returns }\end{array}$ \\
\hline $\begin{array}{l}\text { Correlation between data on } \\
\text { static and dynamic approaches }\end{array}$ & 0.46 & 0.54 & 0.74 & 0.33 \\
\hline \multicolumn{5}{|c|}{$\begin{array}{l}\text { This table presents coefficient estimates from correlation analysis. The first column reports data used in correlation } \\
\text { analysis: static and dynamic approach; the second column shows parameter estimates for the case of frequency o } \\
\text { negative abnormal returns; the third column reports parameter estimates for the case of frequency of positiv } \\
\text { abnormal returns; the fourth column provides parameter estimates for the case of frequency delta and the fiftl } \\
\text { column shows parameter estimates for the case of overall frequency of abnormal returns. }\end{array}$} \\
\hline
\end{tabular}

Table 3. Correlation analysis of data from the static and dynamic approaches.

\begin{tabular}{lrrrr}
\hline Approach & \multicolumn{2}{c}{ Dynamic } & \multicolumn{2}{c}{ Static } \\
\hline Parameter/Price data & Close & Returns & Close & Returns \\
Frequency of negative abnormal returns & 0.01 & -0.56 & -0.07 & -0.47 \\
Frequency of positive abnormal returns & 0.04 & 0.59 & -0.04 & 0.41 \\
Frequency delta & 0.02 & 0.76 & 0.03 & 0.79 \\
Overall frequency of abnormal returns & 0.04 & -0.01 & -0.07 & -0.05 \\
\hline
\end{tabular}

This table presents coefficient estimates from correlation analysis of data from the static and dynamic approaches. The first column reports approach used in correlation analysis; the second and the third columns shows parameter estimates for the case of dynamic approach with close and returns based data respectively; the fourth and the fifth columns shows parameter estimates for the case of static approach with close and returns based data respectively. 
Table 4. Correlation coefficients between the frequency of abnormal returns and monthly returns.

\begin{tabular}{lrrrrrrr}
\hline Parameter & EURUSD & GBPUSD & USDJPY & USDCAD & AUDUSD & EURJPY & GBPCHF \\
\hline Frequency of negative abnormal returns & -0.56 & -0.61 & -0.57 & -0.46 & -0.63 & -0.57 & -0.59 \\
Frequency of positive abnormal returns & 0.59 & 0.49 & 0.50 & 0.61 & 0.38 & 0.36 & 0.33 \\
Frequency delta & 0.76 & 0.74 & 0.73 & 0.72 & 0.70 & 0.71 & 0.66 \\
\hline
\end{tabular}

This table presents coefficient estimates from correlation analysis of frequency of abnormal returns and monthly returns. The first column reports parameter estimates used in correlation analysis: Frequency of negative abnormal returns, Frequency of positive abnormal returns, Frequency delta; the second, the third, the fourth, the fifth, the sixth, the seventh and the eighth column shows parameter estimates for the case of EURUSD, GBPUSD, USDJPY, USDCAD, AUDUSD, EURJPY and GBPCHF respectively.

abnormal returns, as well as the frequency delta between the number of positive and negative abnormal returns and monthly returns.

As can be seen, there is negative (positive) correlation between the frequency of negative (positive) abnormal returns and price dynamics in the FOREX, and the frequency delta has the highest (positive) correlation coefficient, which implies that this variable is the most informative about price movements.

As a further check, we carry out cross-correlation analysis also at the time intervals $t$ and $t+i$, where $I \in\{-10, \ldots, 10\}$. Figures D.1-D.7 reports the cross-correlation between returns and the frequency of (both positive and negative) abnormal returns for the whole sample period for different leads and lags. The highest coefficient corresponds to lag length zero, which means that there is no need to shift the data.

Additional evidence is provided by Granger causality tests (Granger, 1969) between returns in the FOREX and the frequency of abnormal returns (both positive and negative, and also for their delta). The results are presented in Appendix G, Table G.1. As can be seen, the null hypothesis of no causality cannot be rejected in any case (the single exception is USDJPY).

The next step is to test $\mathrm{H} 1$ by running a number of simple linear regressions for returns against the frequency of negative and positive abnormal returns and the delta frequency, as well as regressions with dummy variables (see Section 3 for details). The results are presented in Appendix E, Tables E.1-E.7. As can be seen, all the regressors are statistically significant. Both actual and estimated values are plotted in Figures H.1-H.7. The latter appear to capture well the behaviour of the former. Various diagnostic tests for the models from Tables E.1-E.7 are reported in Table 5, and suggest that the estimated models have the appropriate functional form and their residuals are not autocorrelated. The model for the EURUSD exchange rate passes all tests, but there is evidence of nonnormality of the residuals in the case of EURJPY, USDJPY, GBPCHF, and both heteroscedasticity of residuals and unstable parameters are present in the models for GBRUSD, AUDUSD and USDCAD.

The best specifications for the linear regression models with the frequency of positive and negative abnormal returns as regressors (as indicated by the R-square for the whole model and the p-values for the estimated coefficients) are presented in Table 6.

The Logit and Probit regression results for the case of price closes are presented in Appendix F, Tables F.1-F.7. These two models produce broadly similar results (with some slight differences in the estimated parameters) and their explanatory power ranges between $73.9 \%$ and $76.3 \%$. On the whole, the evidence supports $\mathrm{H} 1$. 


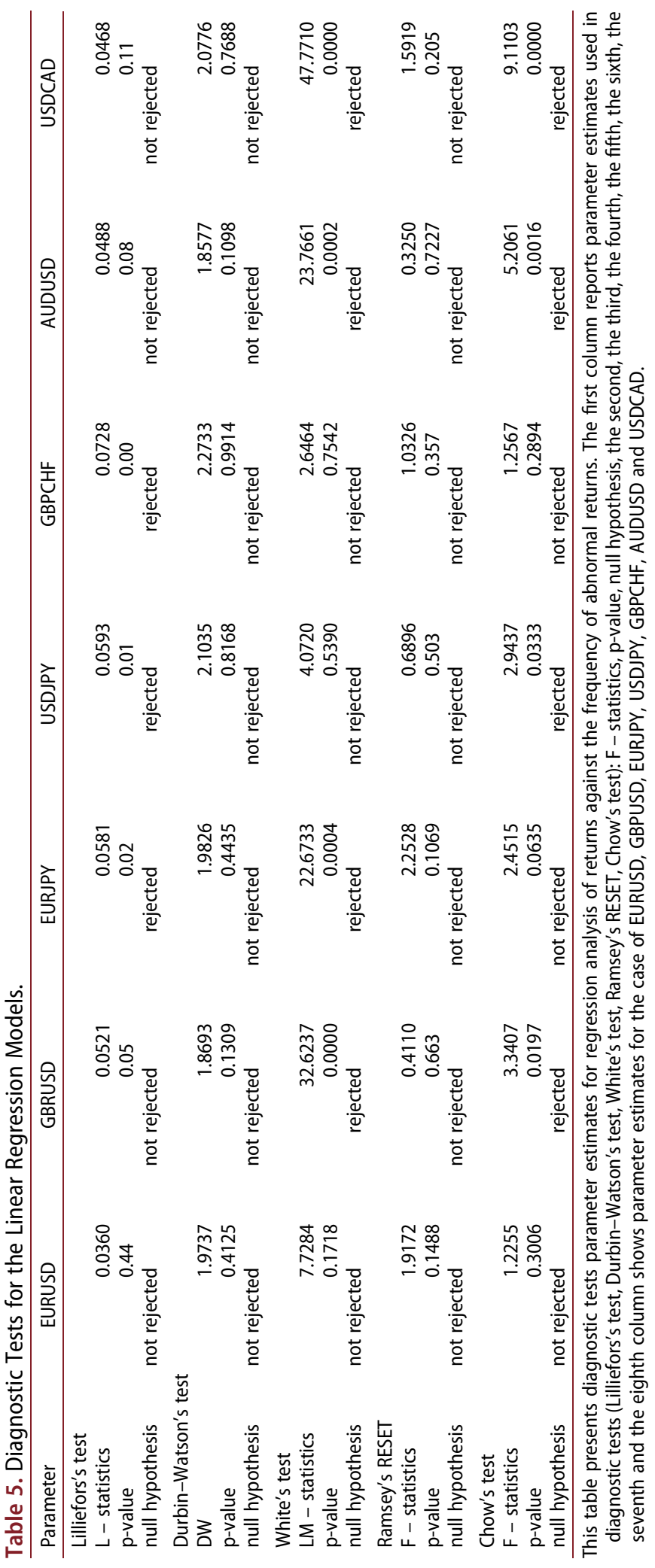


Table 6. Best regression models for returns in the FOREX.

\begin{tabular}{ll}
\hline Instrument & \multicolumn{1}{c}{ Regression with dummy variables } \\
\hline EURUSD & return $_{\mathrm{i}}=-0.0035-0.0101 \times \mathrm{F}_{i}^{-}+0.0119 \times \mathrm{F}_{i}^{+}$ \\
GBPUSD & return $_{\mathrm{i}}=0.0029-0.0102 \times \mathrm{F}_{i}^{-}+0.0079 \times \mathrm{F}_{i}^{+}$ \\
USDJPY & return $_{\mathrm{i}}=0.0025-0.0123 \times \mathrm{F}_{i}^{-}+0.0109 \times \mathrm{F}_{i}^{+}$ \\
USDCAD & return $_{\mathrm{i}}=-0.0050-0.0076 \times \mathrm{F}_{i}^{-}+0.0104 \times \mathrm{F}_{i}^{+}$ \\
AUDUSD & return \\
EURJPY & return $_{\mathrm{i}}=0.0130-0.0146 \times \mathrm{F}_{i}^{-}+0.0093 \times \mathrm{F}_{i}^{+}$ \\
GBPCHF & return $_{\mathrm{i}}=0.0072-0.0115 \times \mathrm{F}_{i}^{-}+0.0078 \times \mathrm{F}_{i}^{+}$ \\
\hline
\end{tabular}

This table presents best regression models for returns in the FOREX. The first column reports instruments, the second column shows models equations for these instruments, where $\mathrm{F}_{i}^{+}\left(\mathrm{F}_{i}^{-}\right)$- frequency of positive (negative) abnormal returns during a period $i$;

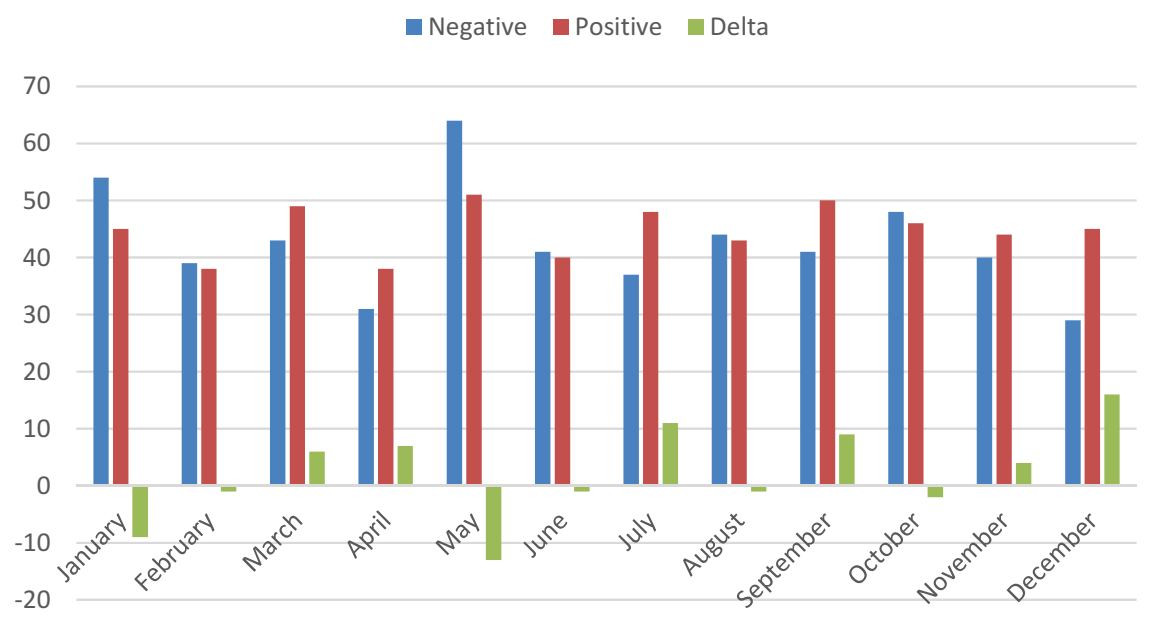

Figure 1. The frequency of abnormal returns by month: the case of EURUSD. This figure presents frequency of abnormal returns divided by months during all the sample period for the case of EURUSD. The "Negative" parameter refers to the frequency of negative abnormal returns; "Positive" parameter refers to the frequency of positive abnormal returns; and "Delta" parameter shows estimates for the difference between the frequency of positive and negative abnormal returns.

Concerning $\mathrm{H} 2$, namely the possible presence of seasonal patterns in in the frequency of abnormal returns, at first we do some visual inspection of the data. Figure 1 displays positive and negative abnormal returns and the delta frequency by month for EURUSD and provides no prima facie evidence of seasonality for the former two, while the latter appears to be negative in January and May and positive in December. Further evidence of seasonal behaviour for the delta frequency is provided by Figure 2, which shows it for all the exchange rates considered.

To see whether these seasonal differences are statistically significant we carry out ANOVA analysis and Kruskal-Wallis tests. The results at the 5\% confidence level are reported in Table 7 and suggest that in most cases there are no significant seasonal patterns, which implies a rejection of $\mathrm{H} 2$.

As for $\mathrm{H} 3$ (parameter stability), first we compute the average number of abnormal returns per year (positive+negative) based on all exchange rates considered; this is displayed in Figure 3. As can be seen, it was lower in the 1990s, and peaked in 2004 
Table 7. Results of ANOVA and non-parametric Kruskal-Wallis tests for statistical differences in the frequency of abnormal returns between different months.

\begin{tabular}{|c|c|c|c|c|c|c|c|}
\hline \multirow[b]{2}{*}{ Instrument } & \multirow[b]{2}{*}{ Parameter } & \multicolumn{3}{|c|}{ ANOVA test } & \multicolumn{3}{|c|}{ Kruskal-Wallis test } \\
\hline & & F - statistics & $p$-value & Null hypothesis & Chi Squared test & $p$-value & Null hypothesis \\
\hline \multirow[t]{4}{*}{ EURUSD } & Returns & 1.648 & 0.0851 & not rejected & 13.8977 & 0.2387 & not rejected \\
\hline & All_over & 2.542 & 0.0044 & rejected & 25.026 & 0.0090 & rejected \\
\hline & Negative & 2.525 & 0.0047 & rejected & 19.550 & 0.0519 & not rejected \\
\hline & Positive & 0.556 & 0.8638 & not rejected & 6.8833 & 0.8084 & not rejected \\
\hline \multirow[t]{4}{*}{ GBRUSD } & Returns & 1.733 & 0.0658 & not rejected & 26.521 & 0.0054 & rejected \\
\hline & All_over & 2.678 & 0.0027 & rejected & 28.368 & 0.0028 & rejected \\
\hline & Negative & 3.146 & 0.0005 & rejected & 35.185 & 0.0002 & rejected \\
\hline & Positive & 1.369 & 0.1870 & not rejected & 15.246 & 0.1715 & not rejected \\
\hline \multirow[t]{4}{*}{ EURJPY } & Returns & 1.290 & 0.2293 & not rejected & 11.817 & 0.3775 & not rejected \\
\hline & All_over & 2.128 & 0.0185 & rejected & 22.608 & 0.0201 & rejected \\
\hline & Negative & 2.355 & 0.0086 & rejected & 24.670 & 0.0102 & rejected \\
\hline & Positive & 1.729 & 0.0667 & not rejected & 18.885 & 0.0632 & not rejected \\
\hline \multirow[t]{4}{*}{ USDJPY } & Returns & 0.635 & 0.7985 & not rejected & 8.388 & 0.6782 & not rejected \\
\hline & All_over & 2.211 & 0.0140 & rejected & 20.198 & 0.0427 & rejected \\
\hline & Negative & 0.919 & 0.5226 & not rejected & 12.713 & 0.3125 & not rejected \\
\hline & Positive & 2.056 & 0.0235 & rejected & 19.827 & 0.0478 & rejected \\
\hline \multirow[t]{4}{*}{ GBPCHF } & Returns & 1.391 & 0.1763 & not rejected & 18.865 & 0.0636 & not rejected \\
\hline & All_over & 0.858 & 0.5826 & not rejected & 11.571 & 0.3967 & not rejected \\
\hline & Negative & 0.788 & 0.6518 & not rejected & 12.439 & 0.3316 & not rejected \\
\hline & Positive & 1.039 & 0.4115 & not rejected & 13.749 & 0.2472 & not rejected \\
\hline \multirow[t]{4}{*}{ AUDUSD } & Returns & 0.982 & 0.4630 & not rejected & 13.627 & 0.2543 & not rejected \\
\hline & All_over & 3.248 & 0.0003 & rejected & 34.741 & 0.0003 & rejected \\
\hline & Negative & 1.226 & 0.2692 & not rejected & 14.342 & 0.2146 & not rejected \\
\hline & Positive & 2.853 & 0.0014 & rejected & 29.822 & 0.0017 & rejected \\
\hline \multirow[t]{4}{*}{ USDCAD } & Returns & 1.119 & 0.3455 & not rejected & 16.630 & 0.1193 & not rejected \\
\hline & All_over & 2.070 & 0.0225 & rejected & 18.512 & 0.0704 & not rejected \\
\hline & Negative & 1.716 & 0.0694 & not rejected & 20.054 & 0.0446 & rejected \\
\hline & Positive & 1.370 & 0.1863 & not rejected & 12.149 & 0.3525 & not rejected \\
\hline
\end{tabular}

This table presents estimates from ANOVA and Kruskal-Wallis tests for statistical differences in the frequency of abnormal returns between different months. The first column reports instruments, the second column shows data used for calculations ("Returns"; "All_over" - parameter shows estimates for the sum of the frequency of positive and negative abnormal returns; "Negative" parameter refers to the frequency of negative abnormal returns; "Positive" parameter refers to the frequency of positive abnormal returns), the third, the fourth and the fifth columns present ANOVA tests estimates: $F$ values, $p$-values and Null hypothesis status respectively; the sixth, the seventh and the eight columns present Kruskal-Wallis tests estimates: Chi Squared test, p-values and Null hypothesis status respectively.

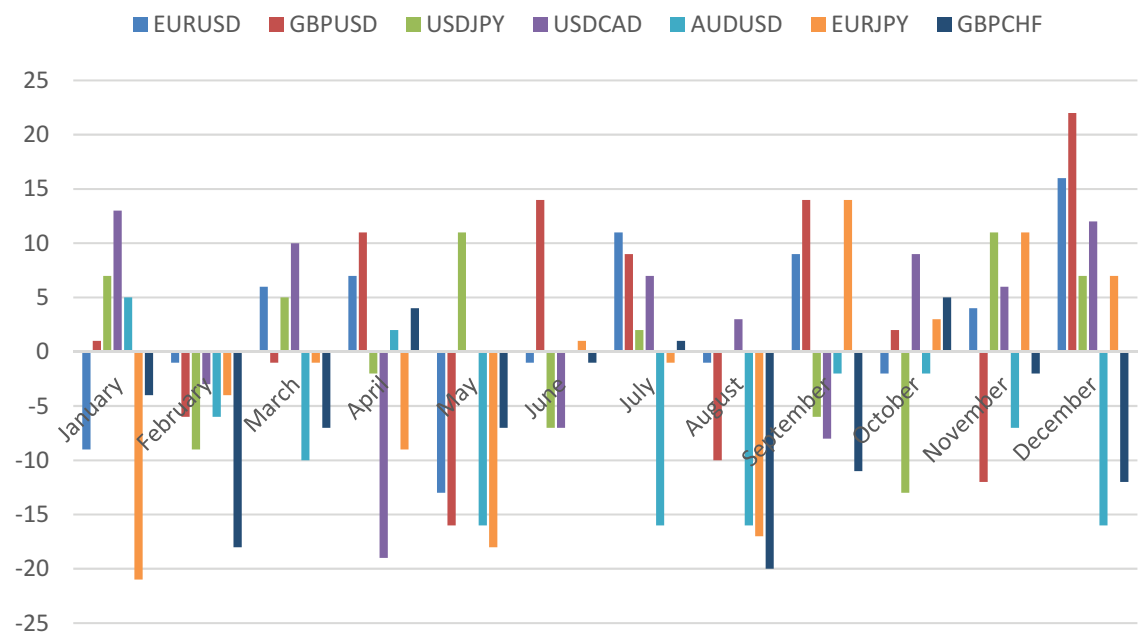

Figure 2. The delta frequency parameter by month. This figure presents the delta frequency parameter divided by months during all the sample period for all of the analyzed instruments. The "Delta" parameter shows estimates for the difference between the frequency of positive and negative abnormal returns. 


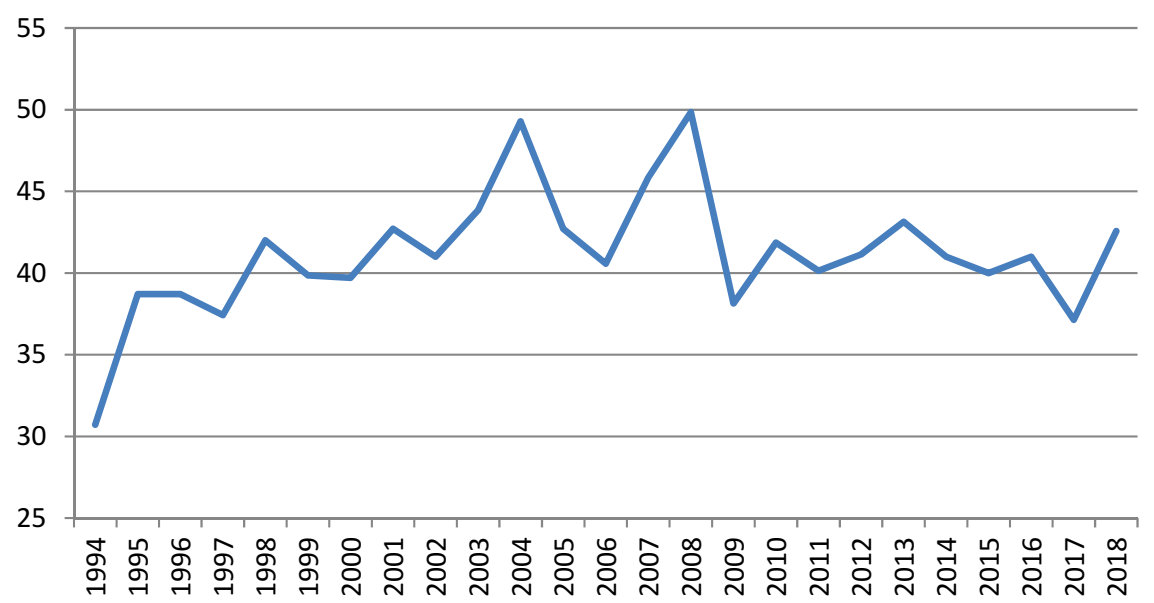

Figure 3. Average frequency of abnormal returns (positive + negative) per year. This figure presents average frequency of abnormal returns per year in the FOREX (based on all exchange rates considered) during all the sample period. The "Average" parameter shows estimates for the sum of the frequency of positive and negative abnormal returns.

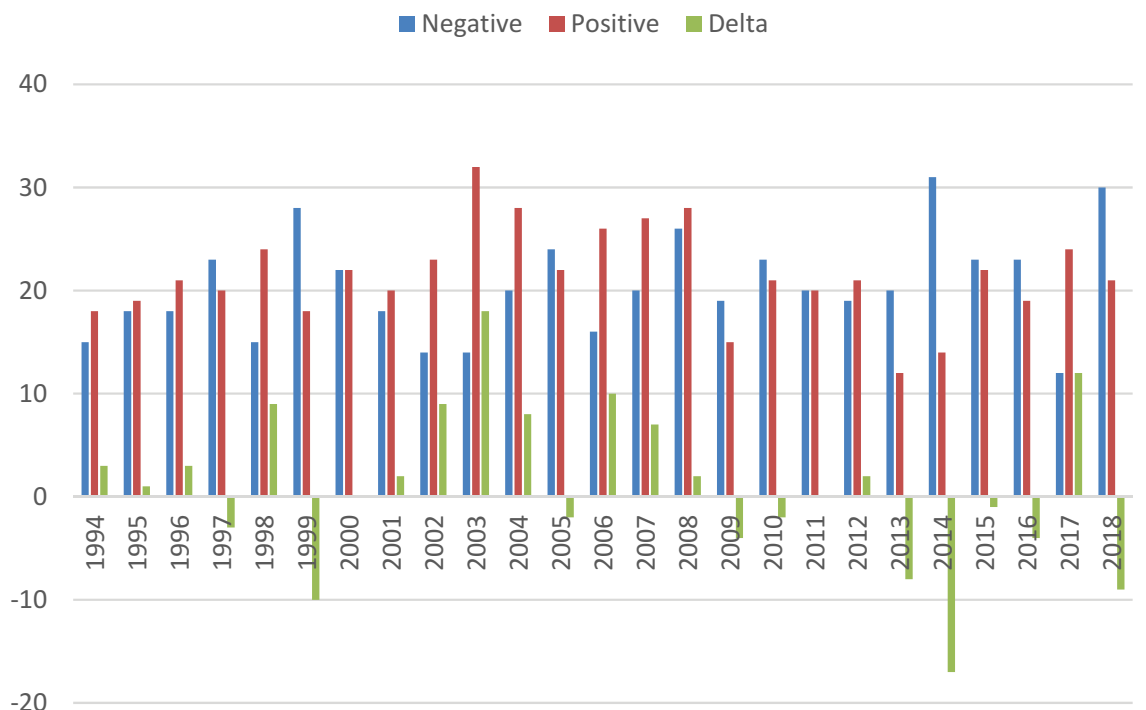

Figure 4. The frequency of abnormal (positive and negative) returns and the delta frequency by year: the case of EURUSD. This figure presents the frequency of abnormal (positive and negative) returns and the delta frequency parameter divided by year during all the sample period for the case of EURUSD. The "Negative" parameter refers to the frequency of negative abnormal returns; "Positive" parameter refers to the frequency of positive abnormal returns; and "Delta" parameter shows estimates for the difference between the frequency of positive and negative abnormal returns.

and 2008, the latter date coinciding with the global financial crisis. More detailed evidence is presented for EURUSD in Figure 4, which suggests the presence of time variation. Finally, the results of the ANOVA analysis and Kruskal-Wallis tests are reported in Table 8 and imply parameter stability, i.e., H3 cannot be rejected. 
Table 8. Results of ANOVA and non-parametric Kruskal-Wallis tests for statistical differences in the frequency of abnormal returns between different years: the case of EURUSD.

\begin{tabular}{|c|c|c|c|c|c|c|}
\hline \multirow[b]{2}{*}{ Parameter } & \multicolumn{3}{|c|}{ ANOVA test } & \multicolumn{3}{|c|}{ Kruskal-Wallis test } \\
\hline & F - statistics & $p$-value & Null hypothesis & Chi Squared test & $p$-value & Null hypothesis \\
\hline Delta & 1.3480 & 0.1323 & not rejected & 23.6846 & 0.2085 & not rejected \\
\hline Negative & 1.1096 & 0.3322 & not rejected & 16.5135 & 0.6228 & not rejected \\
\hline Positive & 1.1145 & 0.3268 & not rejected & 25.4415 & 0.1465 & not rejected \\
\hline
\end{tabular}

This table presents estimates from ANOVA and Kruskal-Wallis tests for statistical differences in the frequency of abnormal returns between different years. The first column reports data used for calculations (The "Negative" parameter refers to the frequency of negative abnormal returns; "Positive" parameter refers to the frequency of positive abnormal returns; and "Delta" parameter shows estimates for the difference between the frequency of positive and negative abnormal returns.), the second, the third and the fourth columns present ANOVA tests estimates: $F$ values, $p$-values and Null hypothesis status respectively; the fifth, the sixth and the seventh columns present Kruskal-Wallis tests estimates: Chi Squared test, $\mathrm{p}$-values and Null hypothesis status respectively.

\section{Conclusions}

This paper investigates the explanatory power of the frequency of one-day abnormal returns in the FOREX for the cases of EURUSD, GBRUSD, USDJPY, EURJPY, GBPCHF, AUDUSD and USDCAD over the period 1994-2019. Using a dynamic trigger approach 4 series are created, specifically the frequency of negative and positive abnormal returns, the difference between the two and the overall frequency of abnormal returns. Then the following hypotheses are tested using a variety of parametric and non-parametric methods: the frequency of abnormal returns is a significant driver of price movements (H1); it does not exhibit seasonal patterns (H2); it is stable over time (H3).

The main findings can be summarised as follows. The frequency of abnormal returns in FOREX has significant explanatory power for returns, is informative about crises (since it increases sharply at the time of a crisis), is not seasonal, and is stable over time. On the whole, our findings suggest that profitable FOREX trading strategies can be designed based on the frequency of abnormal returns, which is evidence of market inefficiency. The difference between actual and estimated returns can be seen as an indication of whether currencies are over - or under-valued and therefore a price increase or decrease should be expected. Obviously currencies should be bought in the case of undervaluation and sold in the case of overvaluation till the divergence between actual and estimated values disappears, at which stage positions should be closed.

\section{Acknowledgments}

We would like to thank an anonymous referee for useful comments and suggestions. The secondnamed author also gratefully acknowledges financial support from the Ministry of Education and Science of Ukraine (0117U003936).

\section{Disclosure statement}

No potential conflict of interest was reported by the author(s). 


\section{Funding}

Alex Plastun gratefully acknowledges financial support from the Ministry of Education and Science of Ukraine (0121U100473)

\section{Notes on contributors}

Guglielmo Maria Caporale (MSc, PhD, LSE) is Professor of Economics and Finance and Director of the Centre for Empirical Finance at Brunel University, London. He is also a Visiting Professor at London South Bank University, a Research Professor at DIW Berlin, a CESifo Research Network Fellow, and an Associate Researcher at the International Laboratory of Financial Economics (LFE), International College of Economics and Finance (ICEF), Higher School of Economics (HSE), Moscow. Prior to taking up his current position, he was a Research Officer at the National Institute of Economic and Social Research in London; a Research Fellow and then a Senior Research Fellow at the Centre for Economic Forecasting at the London Business School; Professor of Economics at the University of East London; Professor of Economics and Finance as well as Director of the Centre for Monetary and Financial Economics at London South Bank University.

Alex Plastun is Professor at the Department of International Economic Relations in the Sumy State University. Before joining Sumy State University, he was a trader and analyst in several investment companies. He still trades in the different financial markets using his own trading strategies. Professor Plastun tries to use his experience as a trader to inform academic theory and is particularly interested in market inefficiencies. He has published in such outlets as the Journal of Economics and Finance, Computational Economics, and Corporate Ownership and Control. Professor Plastun was awarded a PhD in Finance by the Ukrainian Academy of Banking.

Oliynyk Victor is Professor at the Chair of Economic Cybernetics in the Sumy State University. His research interests include actuarial calculations, insurance, optimization and management of financial flows. Professor Oliynyk has published more than 60 scientific and more than 20 pedagogical papers in the areas of finance, economics and mathematics. Professor Oliynyk was awarded a PhD in Physics and Mathematics in 1993.

\section{ORCID}

Guglielmo Maria Caporale (D) http://orcid.org/0000-0002-0144-4135

Alex Plastun (D) http://orcid.org/0000-0001-8208-7135

\section{References}

Andersen, T. G., Bollerslev, T., Diebold, F. X., \& Vega, C. (2003). Micro effects of macro announcements: Real-time price discovery in foreign exchange. American Economic Review, 93(1), 38-62.

Angelovska, J. (2016). Large share price movements, reasons and market reaction. Journal of Contemporary Management Issues, 21, 1-17..

Atkins, A. B., \& Dyl, E. A. (1990). Price reversals, bid-ask spreads, and market efficiency. Journal of Financial \& Quantitative Analysis, 25(4), 535-547.

Barberis, N., Shleifer, A., \& Vishny, R. W. (1998). A Model of Investor Sentiment. Journal of Financial Economics, 49(3), 307-343.

Bartos, J. (2015). Does Bitcoin follow the hypothesis of efficient market? International Journal of Economic Sciences, 4(2), 10-23.

Bremer, M., Hiraki, T., \& Sweeney, R. J. (1997). Predictable Patterns after Large Stock Price Changes on the Tokyo Stock Exchange. Journal of Financial and Quantitative Analysis, 32(3), 345-365. 
Bremer, M., \& Sweeney, R. J. (1991). The Reversal of Large Stock-Price Decreases. Journal of Finance, 46(2), 747-754.

Caporale, G., \& Plastun, A. (2019). On stock price overreactions: Frequency seasonality and information content. Journal of Applied Economics, 22(1), 602-621.

Caporale, G. M., Gil-Alana, L., \& Plastun, A. (2018). Short-term Price Overreactions: Identification. Testing, Exploitation, Computational Economics, 51(4), 913-940.

Caporale, G. M., Plastun, A., \& Oliinyk, V. (2019). Bitcoin fluctuations and the frequency of price overreactions. Financial Markets and Portfolio Management, 33(2), 109-131.

Chelley-Steeley, P. L., \& Tsorakidis, N. (2013). Bid-ask spread dynamics in foreign exchange markets. International Review of Financial Analysis, 29, 119-131.

Chuck, C., Kwok, Y., \& Brooks, L. D. (1990). Examining Event Study Methodologies in Foreign Exchange Markets. Journal of International Business Studies, 21(2), 189-224.

Cox, D. R., \& Peterson, D. R. (1994). Stock returns following large one-day declines: Evidence on short-term reversals and longer-term performance. The Journal of Finance, 49(1), 255-267.

Daniel, K., Hirshleifer, D., \& Subrahmanyam, A. (1998). Investor Psychology and Security Market Under- and Overreactions. Journal of Finance, 53(6), 1839-1886.

Dickey, D. A., \& Fuller, W. A. (1979). Distribution for the estimates for autoregressive time series with a unit root. Journal of the American Statistical Association, 74, 427-431.

Duran, A., \& Caginalp, G. (2007). Overreaction Diamonds: Precursors and Aftershocks for Significant Price Changes. Quantitative Finance, 7(3), 321-342.

Eross, A., McGroarty, F., Urquhart, A., \& Wolfe, S. (2019). The intraday dynamics of bitcoin. Research in International Business and Finance, 49, 71-81.

Evans, M. D., \& Lyons, R. K. (2002). Order flow and exchange rate dynamics. The Journal of Political Economy, 10(1), 170-180.

Govindaraj, S., Livnat, J., Savor, P., \& Zhaoe, C. (2014). Large price changes and subsequent returns. Journal Of Investment Management, 12(3), 31-58.

Granger, C. W. J. (1969). Investigating causal relations by econometric models and cross-spectral methods. Econometrica, 37(3), 424-438.

Granger, C. W. J., \& Newbold, P. (1986). Forecasting economic time series (Vol. 2). New York, NY: Academic Press.

Griffin, D., \& Tversky, A. (1992). The weighing of evidence and the determinants of confidence. Cognitive Psychology, 24(3), 411-435.

Hong, H., \& Stein, J. C. (1999). A unified theory of underreaction, momentum trading and overreaction in asset markets. Journal of Finance, 54(6), 2143-2184.

Jegadeesh, N., \& Titman, S. (1993). Returns to buying winners and selling losers: Implications for stock market efficiency. The Journal of Finance, 48(1), 65-91.

Jin, W., Livnat, J., \& Zhang, Y. (2012). Option Prices Leading Equity Prices: Do Option Traders Have an Information Advantage? Journal of Accounting Research, 50(2), 401-431.

Kallianiotis, I. (2017). Exchange rate movement: Efficiency in the foreign exchange market. International Research Journal of Applied Finance. VIII(4), 195-213.

Kocenda, E., \& Moravcová, M. (2018). Intraday effect of news on emerging european forex markets: Intraday effect of news on emerging European forex markets. Economic Systems, 42 (4), 597-615.

Kwiatkowski, D., Phillips, P. C. D., Schmidt, P., \& Shin, Y. (1992). Testing the null hypothesis of stationarity against the alternative of a unit root. How sure are we that economic time series have a unit root?. Journal of Econometrics, 54, 159-178.

Lasfer, M. A., Melnik, A., \& Thomas, D. C. (2003). Short-term reaction of stock markets in stressful circumstances. Journal of Banking \& Finance, 27(10), 1959-1977.

Lyons, R. K. (1995). Tests of the microstruture hypothesis in the foreign exchange market. Journal of Financial Economics, 39(2-3), 321-351.

Madura, J., \& Richie, N. (2004). Overreaction of exchange traded funds during the bubble of 19982002. Journal of Behavioral Finance, 5(2), 91-104.

Oh, G., Kim, S., \& Eom, C. (2006). Market Efficiency in Foreign Exchange Markets. Physica A: Statistical Mechanics and Its Applications, 382(1), 209-212. 
Olson, D. (2004). Have trading rule profits in the currency markets declined over time? Journal of Banking and Finance, 28(1), 85-105.

Parikakis, G. S., \& Syriopoulos, T. (2008). Contrarian strategy and overreaction in foreign exchange markets. Research in International Business and Finance, 22(3), 319-324.

Phillips, P., \& Perron, P. (1988). Testing for a unit root in time series regression. Biometrika, 75(2), 335-346.

Pritamani, M., \& Singal, V. (2001). Return predictability following large price changes and information releases. Journal of Banking \& Finance, 25(4), 631-656.

Rao, A. S., \& Gertler, M. (1999). Overreaction of asset prices in general equilibrium. Review of Economic Dynamics, 2(1), 3-35.

Sandoval, L., \& Franca, I. (2012). Correlation of financial markets in times of crisis. Physica A: Statistical Mechanics and Its Applications, 391(1-2), 187-208.

Savor, P. (2012). Stock returns after major price shocks: The impact of information. Journal of Financial Economics, 106(3), 635-659.

Schnusenberg, O., \& Madura, J. (2001). Do US stock market indexes over-or under react? Journal of Financial Research, 24(2), 179-204.

Serbinenko, A., \& Rachev, S. (2009). Intraday spot foreign exchange market. Analysis of efficiency, liquidity and volatility. In Investment management and financial innovations (Vol. 6, pp. 35-45). LLC "Consulting Publishing Company "Business Perspectives".

Wan, J.-Y., \& Kao, C.-W. (2009). Evidence on the contrarian trading in foreign exchange markets. Economic Modelling, 26(6), 1420-1431.

Wong, M. (1997). Abnormal stock returns following large one-day advances and declines. Evidence from Asian-Pacific Markets, Financial Engineering and Japanese Markets, 4, 71-177. 